\title{
A REVIEW: FLOOR CRANES FOR INDUSTRIAL USE
}

\author{
Abhinav R.Duragkar ${ }^{1}$, S. N. Sakhale ${ }^{2}$, M.S.Lande ${ }^{3}$ \\ ${ }^{1}$ M.Tech Student, Department of Mechanical Engineering, PCOE, Nagpur - 440019 \\ ${ }^{2}$ Associate Professor, Department of Mechanical Engineering, PCOE, Nagpur - 440019 \\ ${ }^{3}$ Assistant Professor, Department of Mechanical Engineering, PCOE Nagpur - 440019
}

\begin{abstract}
In day today Industrial practice material handling is a important phenomenon and can be defined as handling, movement, storage and control of materials or equipments throughout the entire process of manufacturing and in between the various process which are necessary to create a finish good. As a process material handling incorporates a wide range of manual, semi-automated and automated tools and equipments. In a manufacturing unit material handling equipment is designed on basis of specific need, nature of work, ergonomics, space utilization and life cycle cost. Equipment's such as powered trucks, Conveyors, pallets, hoists, cranes etc. are some of the commonly used material handling devices in industries. For moving load over a short distance cranes are the most effective type of material handling system and can be used for heavy loads also. These material handling cranes can be movable or fixed type. Movable cranes are flexible and economical way of moving the material from one place to another and requires a manual control.
\end{abstract}

Keywords: Floor Crane, Winch, Hydraulic Cylinder, Hydraulic Relief Valve, Telescopic Boom, Lithium Ion Battery.

\section{INTRODUCTION}

A floor crane is equipment, generally equipped with a lifting mechanism such as a hoist with wire Ropes or hydraulic cylinder that can be used both to lift and lower materials and prior to the horizontal movement of the crane. It is mainly used for lifting load from 50 to $2000 \mathrm{~kg}$. It uses one or more simple mechanism to create mechanical advantage and thus moves loads beyond the human capability. This crane is commonly employed in the transport industry for the loading and unloading of low volume material in transport vehicles, in the construction industry for the movement of building materials and in the manufacturing industry for the assembling of heavy equipment. In material handling, the floor cranes play a vital role in manufacturing industries. These Hydraulic floor Cranes, provide an efficient low cost alternative to other material handling equipment. Strong, robust, study and built to very standard. Laden, these cranes are maneuverable and loading, unloading and shifting of heavy load. Crane structure consists of a base frame, mast, boom, hoisting arrangement, wheels and locking device etc. Generally the cranes available in manual type but can also be motorized. In floor cranes balancing is done on the using a rest base design or a counter weight. The stability of these cranes is quite high and tipping analysis of such cranes shows it as very stable equipment.

\section{FLOOR CRANES CONSTRUCTION}

A floor crane is a portable type of device as shown in fig below. It is a tubular and rigid and light weight structure and consists of base frame having rollers for movement on the floor. A vertical post called as a mast is welded on the base frame and is further strengthened by giving bracings on both sides. A horizontal boom is connected to the mast by a pin joint. The boom is having a lifting hook at the end and is supported in middle region by a member connecting in with lower region of mast.

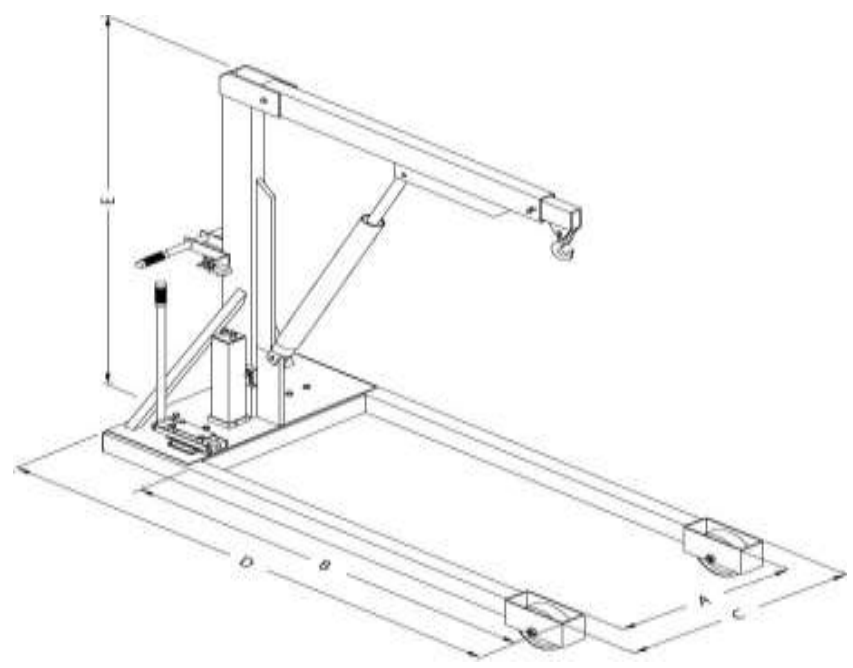

Fig.1 Typical floor crane

\section{CRANE PARTS}

The mobile crane consists of various parts forming a mechanism that would give a mechanical advantage in lifting heavy loads and moving the same. The parts are generally made up of hollow steel tubes.

\subsection{The Boom}

The boom is horizontal member of floor crane which is attached to the vertical post at one and a lifting hook is attached to other end. The boom used is in the form of a cantilever member. The boom is generally telescopic type. The length of the boom can be varied based on the weight and size of the equipment to be lifted. 


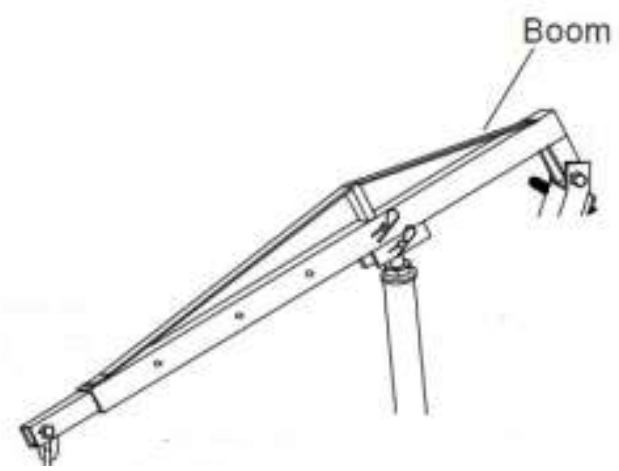

Fig.2 Arrangement of Boom

\subsection{The Mast}

The mast is a vertical member of the crane which supports the boom as well as the lifting member of the crane. It is welded on the base frame and connected to the boom via a pin joint in vertical plain.

\subsection{The Base}

The base is a part that gives balance and rigidness to the crane structure. It is generally in V shape. It can be noted that balance of the crane is due to rest base design or a counter weight is to balance the load which is lifted.

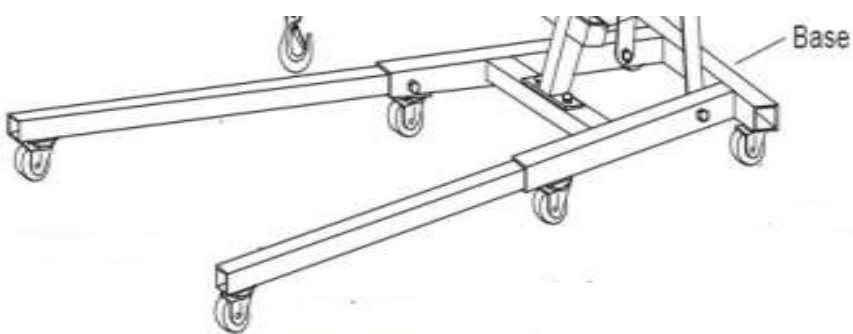

Fig.3 Floor crane base

\subsection{Roller Members}

These are the components which make the mobility of crane possible. This can be metallic rollers with bearing or rubber wheels.

\subsection{Lifting Mechanism}

The mechanism is used for lifting the load for further movement of the load. It has two types of movement, one for elevating the load and other for lowering.

\subsection{Locking Mechanism}

This mechanism is used to lock the load in suspended position for further movement. A locking device is highly necessary for safe material handling operation.

\section{TYPES OF FLOOR CRANES}

'Floor crane is lifting and shifting equipment like a crane. They are available in both manual and electro-hydraulic modes of operation. The floor cranes can be differentiated on basis of
1) Lifting Mechanism

2) Driven Power

3) Method of Load Balancing

\subsection{Floor Cranes with Lifting Mechanism}

\subsubsection{Floor Cranes with Hydraulic Piston Cylinder}

It consists of a hydraulic cylinder piston which can be actuated manually to lift or lower the load. A manual pumping action in carried out by use of a handle which pumps hydraulic Fluid inside the cylinder from the hydraulic tank which raises the piston thereby deflecting the boom in vertical plane which lifts the material and vice versa. The tank is inbuilt below the cylinder casing. A foot pump can also be used for pumping action instead of hand pumping. The lowering action boom is done by a relief valve which slowly returns the hydraulic fluid back into the hydraulic tank. This slow movement of fluid is necessary so that the boom is lowered slowly which avoids sudden fall of load on ground. A hydraulic power pack can be used to make the process automated without any manual efforts required.

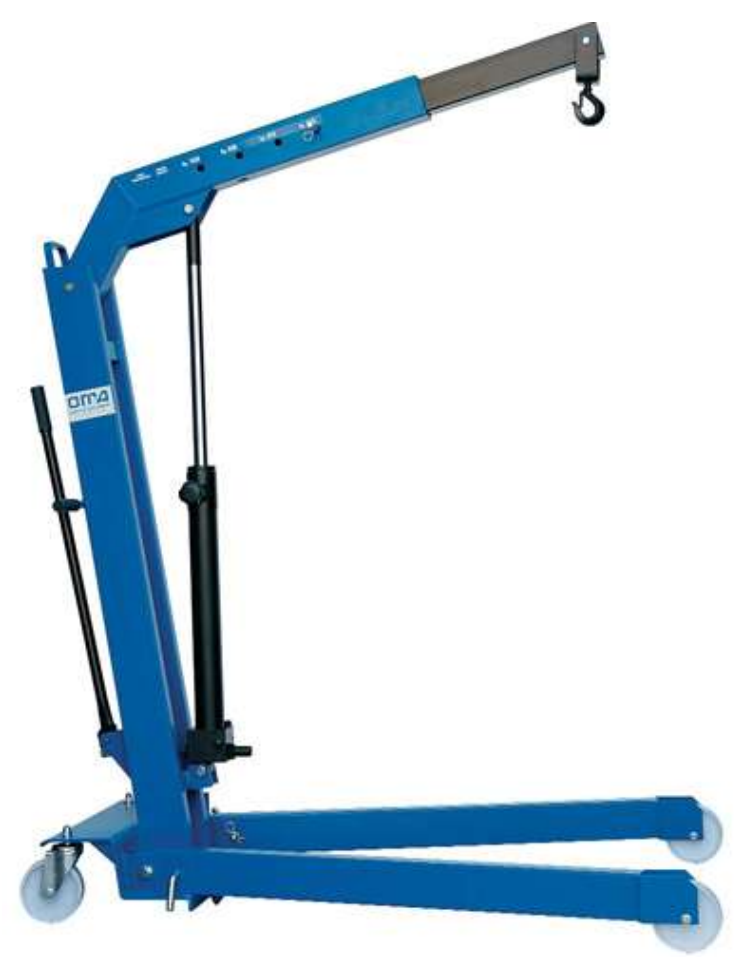

Fig.4 Floor crane with hydraulic cylinder

\subsubsection{Floor Cranes with Winch}

These types of floor crane consist of a winch arrangement. The winch rope is run over metallic pulleys and is suspended from the end of the boom to the end of which a lifting hook is attached. The winch may be hand operated or powered by a DC motor and can be moved in both in reverse and forward direction. A dynamic Auto braking system within the winch drum is necessary for holding the load in suspended position. A $12 \mathrm{~V}$ battery is required for supplying power in case of a powered winch. Fig 5 shows a winch use in floor crane. 


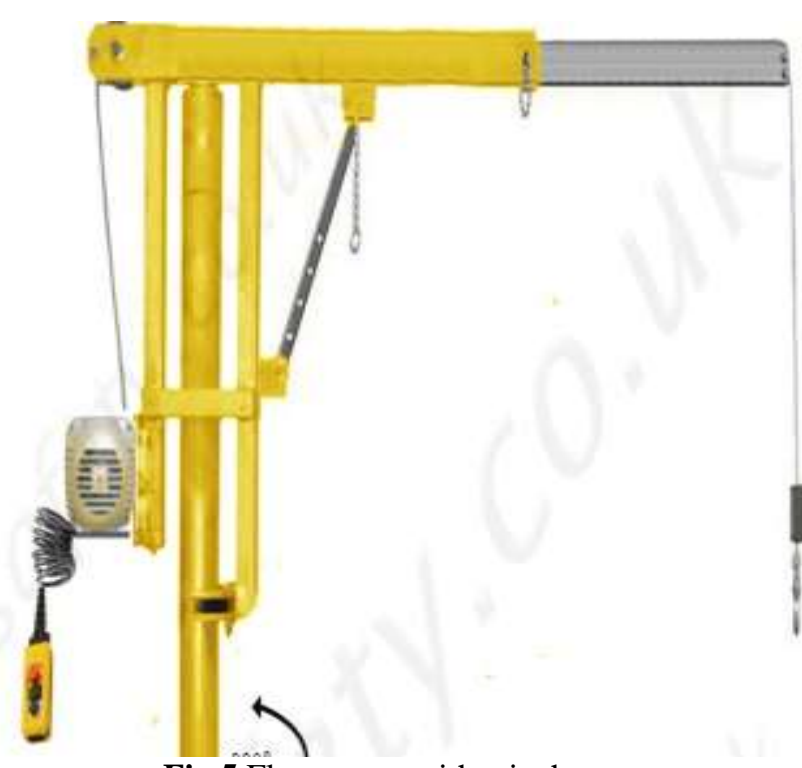

Fig.5 Floor crane with winch

\subsubsection{Floor Cranes with Mechanical Lead Screw}

It consists of a lead screw arrangement as shown in fig 6. The supporting member is in form of two lead screws having treads in opposite direction and inside the same housing which is treaded internally. When the housing is rotated in a particular direction the screw moves forward lifting the boom in relative to the mast in upward direction and hence causing a lifting action. The screw provides a mechanical advantage on human efforts for lifting a particular load. This type of lifting arrangement is quite slow and time consuming.

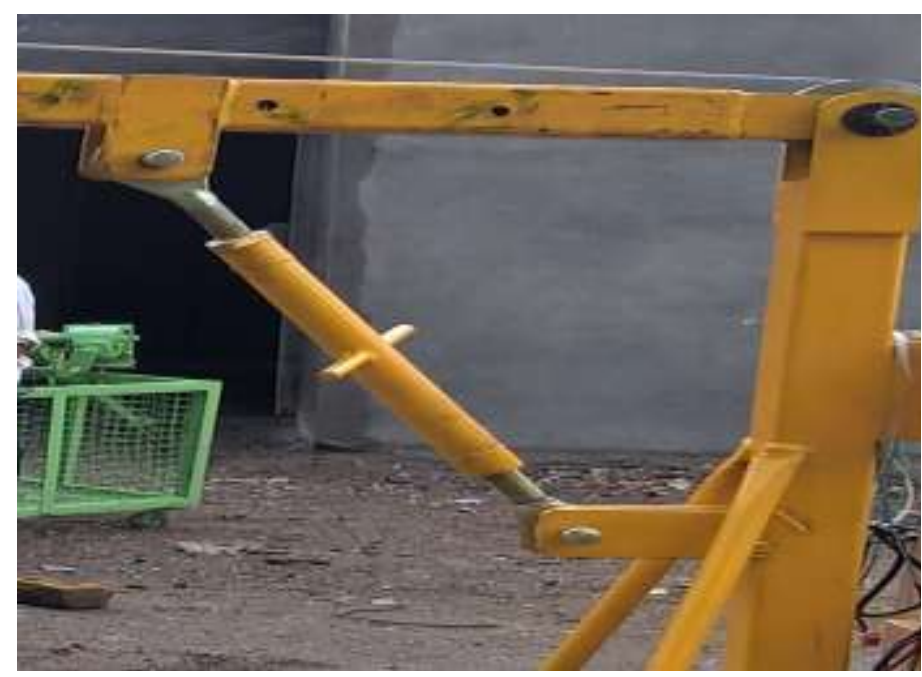

Fig.6 Floor crane with mechanical lead screw

\subsection{Floor Cranes with Driven Power}

\subsubsection{Manual Push Type Floor Crane}

The floor crane in this type is moved by purely using human efforts. A pushing handle is given provided on mast by help of which human force can be applied to move the crane after load is being lifted. For higher load beyond 1 Ton it is quite difficult to push the same manually and hence a machine driven version is more useful.

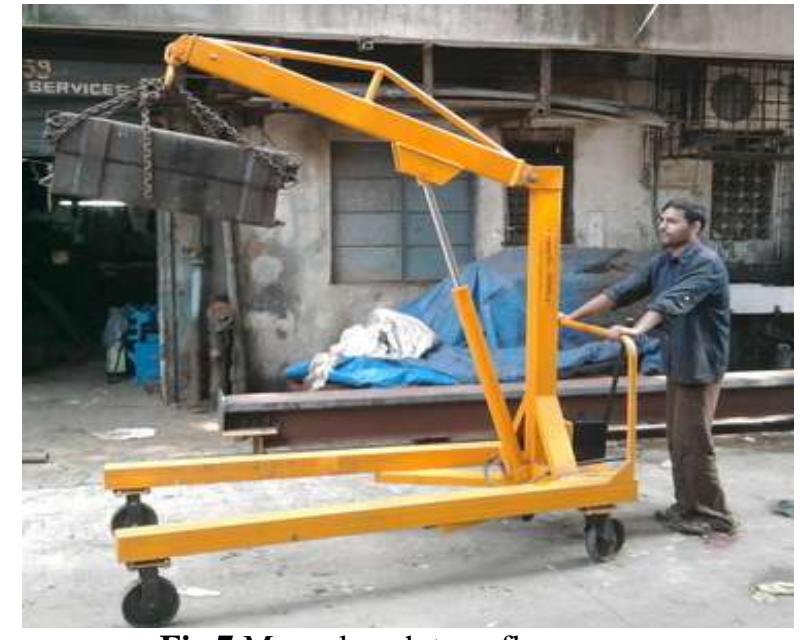

Fig.7 Manual push type floor crane

\subsubsection{Motor Driven Type Floor Crane}

The floor crane incorporates a drive power source for moving the crane. The drive source may be a battery operated DC motor or a 4 stroke Engine. Human efforts are saved in this version of floor crane.

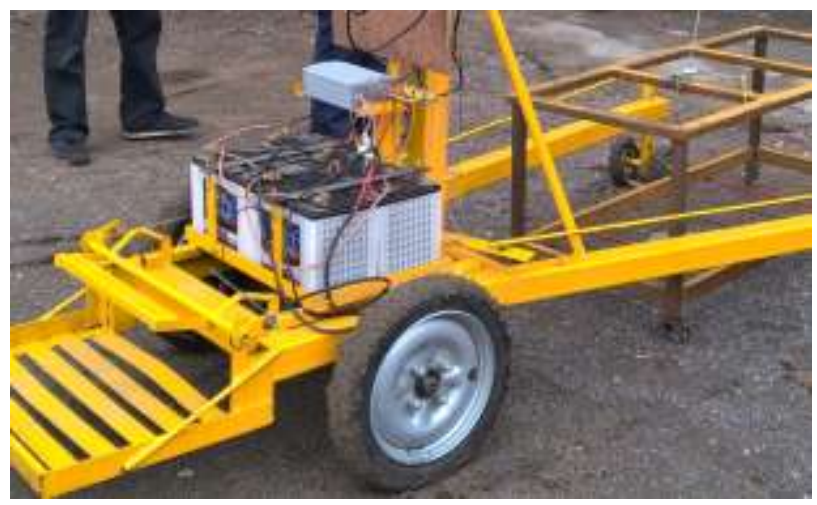

Fig.8 Motor driven floor crane

\subsection{Floor Cranes by Method of Load Balancing}

\subsubsection{Rest Base Type Floor Crane}

In this type of floor crane the Load is distributed equally among the 4 wheels of contact and hence the tipping is avoided. This is also called as the self-balance type of crane.

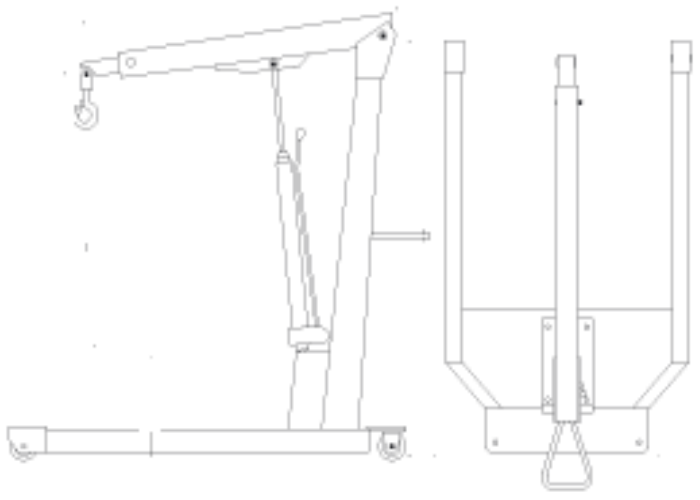

Fig.9 Rest base type floor crane 


\subsubsection{Counter Weight Balance Floor Crane}

In this type of crane the balance is maintained by using a counter weight. The counter weight is increased or decreased based on the load to be lifted. This type is also called as counter balance type of floor crane.

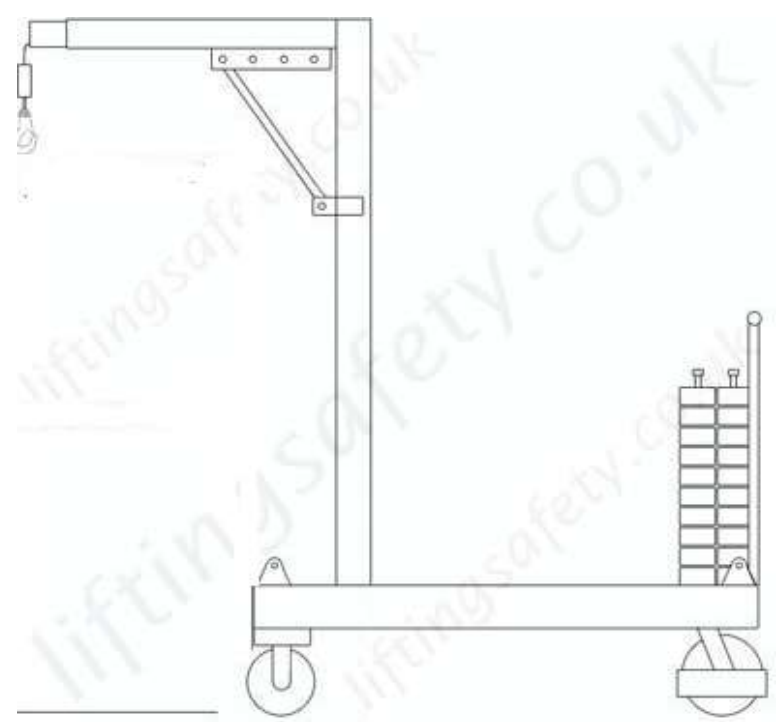

Fig.10 Counter weight balance floor crane

\section{CONCLUSION}

Floor crane is a very economical, time saving, safe, and easy to handle device which can be used for varying load from 50 $\mathrm{kg}$ to $2000 \mathrm{~kg}$. It can be a very useful device in improving the productivity in day today industrial setup. Further improvement can be done in floor crane design by making it more compact, light in weight and portable. A space for operators sitting arrangement is also feasible. This additional weight of operator can be used as a counter weight.

\section{REFERENCES}

[1]. Okolie Paul Chukwulozie, "Steel work design and analysis of floor cranes", British Journal of Applied Science \& Technology| Article No.BJAST.23079 May 2015 ISSN ISSN: 2231-0843, NLM ID: 101664541

[2]. V Jose Ananth Vino, "International Journal of Biotech Trends and Technology (IJBTT)"' -Volume 2/ Issue 1/ Number 1- Jan 2012," ISSN: 2249-0183.

[3]. A Balaji, H Jahir Hussein, "International Journal of Science and Engineering Applications" Volume 3 Issue 5, 2014, ISSN-2319-7560 (Online).

\section{WEBSITES}

[1] www.sciencedirect.com

[2] www.sciencedaily.com

[3] www.sciencedomain.org 